\title{
Cylinder Implantation - A New Method for Endoscopic Treatment of Anastomotic Dehiscence
}

\begin{abstract}
Mediastinal anastomotic leaks after surgery on the upper gastrointestinal tract are highly prevalent complications, occurring in $5-15 \%$ of cases, with a mortality of about $60 \%$ [1]. Endoscopic techniques are increasingly used for the treatment of partially insufficient anastomoses. The procedure consists of endoscopic drainage, lavage and wound closure using fibrin glue [2]. This report describes an additional implantation of a Vicryl cylinder into the fistula.
\end{abstract}

A 61-year-old man with an intestinal-type adenocarcinoma at the gastroesophageal junction underwent resection and intrathoracic, circular-stapled esophagogastrostomy. A dehiscence of $1 \times 2 \mathrm{~cm}$ and a mediastinal abscess $3 \times 6 \mathrm{~cm}$ in size were diagnosed by means of esophagoscopy, contrast study, and $\mathrm{CT}$ on the fifth postoperative day. CTcontrolled percutaneous drainage using a pigtail catheter was performed. The dehiscence was endoscopically cleaned three times at two-day intervals. Afterwards, $2 \mathrm{ml}$ of fibrin glue were injected into the submucosa on the fistula site. This procedure was repeated on three subsequent days, resulting in a decline in the size of the dehiscence. A Vicryl cylinder about 8 $10 \mathrm{~mm}$ in diameter was implanted by endoscopy (Figures $\mathbf{1}$ and $\mathbf{2}$ ). Immediately after implantation, the patient became afebrile. The external pigtail drain was removed on the 15 th postoperative day. Oral nutrition was started three days after the leak closure, and the patient was discharged 22 days after the esophagogastrostomy. Two months later, the anastomosis was regularly epithelialized and histological findings confirmed regular granulation tissue. The patient has now been asymptomatic for one year.

The endoscopic treatment of partially insufficient anastomoses is a successful therapeutic option $[3,4]$. The additional implantation of a Vicryl cylinder provides, as described here, safe and fast closure of the fistula. The material of the cylinder is resorbable, and has been extensively clinically tested [5]. We suggest that the combination of fibrin glue and liquid synthetic material, which polymerizes after application and is subsequently resorbed, is likely to be a convenient option for the treatment of partial anastomotic dehiscences in the upper gastrointestinal tract.

M. Pross, T. Manger, T. Reinheckel,

R. Mantke, H. Lippert

Dept. of Surgery,

Otto-von-Guericke University,

Magdeburg, Germany 

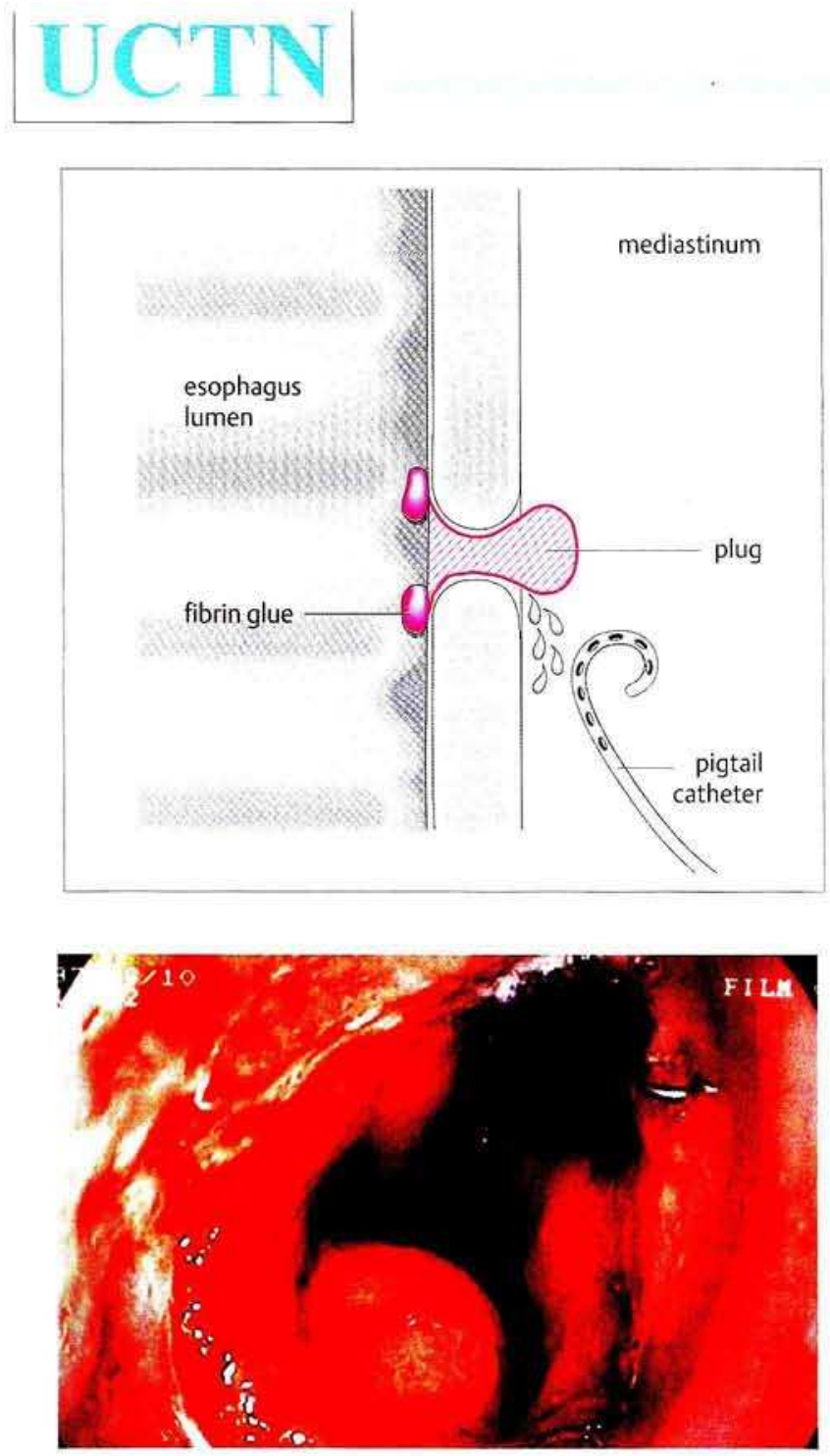

Unusual Cases and Technical Notes s 103

Figure 1 Diagram of the cylinder (length $16 \mathrm{~mm}$, diameter $8 \mathrm{~mm}$ ) plugging the fistula. The mediastinum is drained by a pigtail catheter. The luminal surface of the cylinder was sealed with fibrin

Figure 2 Endoscopic image of the implanted cylinder

\section{References}

1. Urschel JD. Esophagogastrostomy anastomotic leaks complicating esophagectomy: a review. Am J Surg 1995; 169: $634-40$

2. Groitl H, Horbach T. Endoscopic treatment of anatomosis insufficiency and perforation in the esophagus with fibrin glue. Langenbecks Arch Chir Suppl Kongressbd 1996; 113: 753-4

3. Cellier C, Landi B, Faye A, et al. Upper gastrointestinal tract fistulae: endoscopic obliteration with fibrin sealant Gastrointest Endosc 1996; 44: 731 -3

4. Jorgensen JO, Hunt DR. Endoscopic drainage of esophageal suture line leaks. Am J Surg 1993; 165: 362-4

5. Brenner J. Mesh materials in hernia repair. In: Schumpelick V, Wantz GE, editors. Inguinal hernia repair. Expert meeting on hernia surgery, St. Moritz. Basel: Karger, 1995; 172-9

Corresponding Author

M. Pross, M.D.

Otto-von-Guericke-Universität

Magdeburg, Medizinische Fakultät

Klinik für Chirurgie

Leipziger Straße 44

39120 Magdeburg

Germany

Fax: $\quad+49(391) 671-5570$

E-mail: Matthias.Pross@medizin.unimagdeburg.de 